\title{
IIFS
}

\section{Public AND PRIVATE CHOICE IN UK HEALTH INSURANCE}

\author{
John Hall \\ Ian Preston
}




\title{
Public and Private Choice in UK Health Insurance*
}

\author{
John Hall \\ Institute for Fiscal Studies \\ Ian Preston \\ University College London and Institute for Fiscal Studies
}

November 10, 1998

${ }^{*}$ We are grateful for the comments of Timothy Besley, Richard Blundell, Costas Meghir and participants at seminars in Colchester, Dundee, London, Tilburg and Toulouse. This research was funded by the Economic and Social Research Council as part of the Economic Beliefs and Behaviour Programme. Data from the British Social Attitudes Survey was provided by Social and Community Planning Research. 


\section{Executive Summary}

Many parts of the public sector coexist with private provision of similar services and in such circumstances we may expect to find interaction between public and private choices. Quality of publicly provided services will be a central influence on decisions whether to make use of private substitutes and use of private substitutes will feed back into attitudes towards the level of public spending. In this paper we present evidence using the British Social Attitudes Survey to show that individual take up of private medical insurance inhibits support for spending on the public health sector. Such effects have been shown to be appreciable and allowance for the joint determination of insurance decisions and attitudes magnifies the size of the estimated effects. 


\section{Introduction}

In the face of continual upward pressure on public health spending caused by, among other things, demographic change, the rarity of labour saving technical progress and the introduction of increasingly costly new medical technology, governments have been keen to encourage growth in private medical insurance to relieve pressure on public budgets. Given fixed public spending, the distributional implications of this may be expected to be progressive as individuals who opt out and thereby free up resources for others are primarily well-off yet continue to contribute to the financing of the public health service through their taxes (see Blackorby and Donaldson 1988, Besley and Coate 1991). A case on grounds of allocative efficiency for allowing opting out by individuals willing to pay to do so also seems clear. Despite this, support for encouraging expansion of the private sector is often tempered by a fear that public sector health spending is not fixed and may be undermined. Groups opting out may well, it is sometimes argued, cease to support spending on public health services so vigorously and official encouragement to private provision could, in a commonly feared scenario, set in motion a downward spiral with an increasingly impoverished public health sector serving an increasingly poor clientele. Against this one has to recognise, as pointed out by Epple and Romano (1996b), that opting out by some reduces the cost of public health provision for those remaining and support from them may be strengthened.

Political equilibrium arises from interplay between public and private choice, with levels of public sector quality driving individual decisions to opt for private sector alternatives and private sector provision driving levels of political support for the quality of public services. The nature of equilibria in systems with public and private provision have been investigated in a number of papers (see Barzel 1973, Epple and Romano 1996a, 1996b, Gouveia 1997, Glomm and Ravikumar 1998, Casamatta, Cremer and Pestieau 1997). Some of these consider cases where private purchases supplement public provision and others cases where they replace it. Epple and Romano (1996b) provide an example of the latter case in which equilibrium can involve the richer publicly insured individuals voting against a coalition of the privately insured and the poorer publicly insured. In calibrated numerical calculations they find public spending to be relatively insensitive to government incentives for private insurance.

Empirical evidence on the magnitude of the interactions between the two sec- 
tors is scant. Cutler and Gruber (1996) and Besley, Hall and Preston (1999) look at the impact of public sector health service quality on private insurance decisions, the former using data from the US and the latter from the UK. Both find evidence that poorer public sector quality may encourage greater take up of private health insurance. To that extent, evidence exists to corroborate one side of the story. In this paper we look at the other link, investigating the way in which support for public health spending is affected by private health insurance coverage. We do this at the individual level, using attitudinal data from a series of large scale British surveys.

The paper is organised as follows. Section 2 presents a brief over-view of the institutional structure and main characteristics of the United Kingdom health care sector. Section 3 describes an illustrative model of public and private sector choice in UK health insurance. Our empirical approach and the data set used to test the model are described in sections 4 and 5. Section 6 presents our results. Section 7 concludes.

\section{The UK Health Sector}

The United Kingdom health care sector is characterised by a dominant public sector provider, known as the National Health Service (NHS) alongside a small private sector which provides a limited range of treatments.

The NHS, established in 1948, is financed from general taxation although there are user charges for a limited range of services such as dental care and prescriptions and for use of private facilities while under treatment in NHS hospitals. During the period of our study, the NHS was regionally organised with funds allocated between regions according to fixed formulae which were based on standardised mortality rates. The 16 Regional Health Authorities (RHAs) further divided their funds across 190 lower level authorities on a discretionary basis. Hospital treatment is provided free at the point of use but certain non-urgent treatments are rationed by waiting lists. Bosanquet(1987) found that $87 \%$ of respondents to the British Social Attitudes survey chose "hospital waiting times" as an area of the NHS in need of improvement. Waiting lists have continued to increase so that almost $2 \%$ of the UK population was on some form of waiting list for hospital treatment at the time of writing (Dilnot and Giles,1998). Reducing the length of waiting lists for hospital treatment has recently been adopted as a policy priority by the incoming Labour government (Labour Party, 1997). 
Roughly three quarters of private medical treatments in the UK are financed via private medical insurance and around $17 \%$ of the population are covered by private medical insurance (Bosanquet and Pollard,1997). Just under half of this is provided by employers and taxed as a fringe benefit, whilst policies covering those aged over 65 attracted tax relief between 1990 and 1997. Policies typically cover a limited range of non-urgent treatments where waiting lists for NHS treatment are longest which is, of course, in itself evidence of the intimate connectedness of the two sectors. For example, in the mid 1980s, $16.7 \%$ of non-abortive treatment and $28 \%$ of hip replacements were carried out in the private sector.

\section{A model of health insurance decisions}

In this section we outline a simple model of private health insurance decisions, extending that in Besley, Hall and Preston (1999) to incorporate public as well as private choice decisions. The details of the model are motivated by the institutional features of the UK health sector which generates the data used in the empirical application and the intention is to guide the subsequent estimation procedure.

Suppose individuals face two health risks. With probability $\theta$ an individual suffers illness of the first non-urgent type for which treatment of quality ${ }^{1} q$ (let us call this "elective surgery") is available in the public $\left(q=q^{0}\right)$ or private $\left(q=q^{1}\right)$ sector. With probability $\Theta$ the individual suffers illness of the second urgent type for which treatment of quality $Q$ (let us call this "emergency care") is available in the public sector only. Individuals differ in gross incomes $Y$ and in probabilities of ill health $(\theta, \Theta)$.

Spending on the public health system is $X$ and is financed by tax payments $T(Y, X)$ which may be income related. The quality of public health care is determined by $X$ through resource allocation rules $q^{0}=q^{0}(X)$ and $Q=Q(X)$. Private health care of quality $q^{1}>q^{0}$ is available for a premium which may be related to observable individual characteristics $\pi(\theta)$. Disposable incomes $y$ are thus $y^{1}=Y-\pi(\theta)-T(Y, X)$ if privately insured and $y^{0}=Y-T(Y, X)$ if not.

Given insurance status, utility depends ${ }^{2}$ on quality of each sort of health

\footnotetext{
${ }^{1}$ For simplicity we let $q$ be a scalar but we could easily extend the results to allow quality to have more than one dimension.

${ }^{2}$ We suppress the obvious dependence also on the probabilities of ill health $(\theta, \Theta)$ since these are not choice variables.
} 
care and on disposable income and is written $V(q, Q, y)$. The individual chooses whichever sector gives the higher expected utility so that utility is $V^{*}\left(q^{0}, q^{1}, Q, Y-\right.$ $T(Y, X), \pi(\theta)) \equiv \max \left[V\left(q^{1}, Q, y^{1}\right), V\left(q^{0}, Q, y^{0}\right)\right]$. It is natural to assume normality of elective care $q$ given the level of emergency care $Q$ and normality of emergency care $Q$ given the level of elective care $q$. These are equivalent, respectively, to assuming $\frac{\partial}{\partial y}\left(V_{1} / V_{3}\right)>0$ and $\frac{\partial}{\partial y}\left(V_{2} / V_{3}\right)>0$. We assume also that emergency care $Q$ is not a gross complement for elective care $q$ in the sense that a rise in the price of elective care would not reduce demand for $Q$, which is equivalent to assuming $\frac{\partial}{\partial q}\left(V_{2} / V_{3}\right) \leq 0 .^{3}$

The following proposition summarises the main features of private choice in such a model ${ }^{4}$. Given the normality assumption about elective care, it is richer individuals faced with poorer quality of public care who are most likely to choose private insurance. Low premiums also encourage insurance decisions and this forms part of the justification for our identifying assumptions.

Proposition 3.1. Suppose that anyone purchases private insurance. Then there is a unique gross income $\hat{Y}=\hat{Y}(\theta, \Theta, \pi(\theta), X)$ at which an individual is indifferent between consuming in the two sectors and the individual purchases private insurance if and only if $Y>\hat{Y}$. $\hat{Y}$ is non-decreasing in $q^{0}$ and in $\pi(\theta)$.

Proof Suppose there exists an income $\hat{Y}$ such that

$$
V\left(q^{0}, Q, \hat{Y}\right)-V\left(q^{1}, Q, \hat{Y}-\pi(\theta)\right)=0
$$

so that there is an income at which an individual is indifferent between consuming in the two sectors. Define $R(z)$ as the quality of elective care which would make someone with disposable income $z$ as well off as this

\footnotetext{
${ }^{3}$ A common model to adopt would be an expected utility model. Suppose the health risks are exclusive, and utilities are $u(q, y)$ if in need of elective surgery, $U(Q, y)$ if in need of emergency care and $v(y)$ if well. Expected utility would therefore be

$$
V(q, Q, y)=\theta u(q, y)+\Theta U(Q, y)+(1-\theta-\Theta) v(y)
$$

The standard assumptions $u_{q q}, u_{y y}, U_{Q Q}, U_{y y}, v_{y y}<0$ and $u_{q y}, U_{Q y}>0$ would then suffice for the indicated normality and complementarity properties.

${ }^{4}$ The result generalises that in Besley, Hall and Preston (1999), involving slightly weaker restrictions on preferences, and also echoes results in, for example, Epple and Romano (1996b, p.303).
} 
individual ie

$$
V(R(z), Q, z) \equiv V\left(q^{0}, Q, \hat{Y}\right)=V\left(q^{1}, Q, \hat{Y}-\pi(\theta)\right) .
$$

Then $\partial R / \partial z=-V_{3}(R(z), Q, z) / V_{1}(R(z), Q, z)$.

Now consider the effect of an increase in gross income on utilities in the two sectors at $\hat{Y}$

$$
\begin{aligned}
& V_{3}\left(q^{0}, Q, \hat{Y}\right)-V_{3}\left(q^{1}, Q, \hat{Y}-\pi(\theta)\right) \\
= & V_{3}(R(\hat{Y}), Q, \hat{Y})-V_{3}(R(\hat{Y}-\pi(\theta)), Q, \hat{Y}-\pi(\theta)) \\
= & \int_{\hat{Y}-\pi(\theta)}^{\hat{Y}}\left[V_{31}(R(z), Q, z) \partial R(z) / \partial z+V_{33}(R(z), Q, z)\right] d z \\
= & \int_{\hat{Y}-\pi(\theta)}^{\hat{Y}}\left[-V_{31}(R(z), Q, z) \frac{V_{3}(R(z), Q, z)}{V_{1}(R(z), Q, z)}+V_{33}(R(z), Q, z)\right] d z .
\end{aligned}
$$

The assumption of normality of elective care $\frac{\partial}{\partial y}\left(V_{1} / V_{3}\right)>0$ is equivalent to assuming $-V_{31} \frac{V_{3}}{V_{1}}+V_{33}$ negative everywhere and therefore the integral must be negative. Thus $\hat{Y}$ is unique (assuming continuity of $V$ ) and individuals purchase private insurance if and only if gross income exceeds $\hat{Y}$.

The fact that $\hat{Y}$ is non-decreasing in $q^{0}$ and in $\pi(\theta)$ follows straightforwardly from differentiating (3.1).

Private willingness to pay for increases in public health spending is given by

$$
\xi(q, Q, y) \equiv \frac{V_{1}(q, Q, y)(\partial q / \partial X)+V_{2}(q, Q, y)(\partial Q / \partial X)}{V_{3}(q, Q, y)}
$$

where $\partial q / \partial X=0$ if the individual is privately insured and $\partial q / \partial X=\partial q^{0} / \partial X$ if not. In an obvious notation, we use $\xi^{1}$ and $\xi^{0}$ in the two circumstances. A self interested individual would support a marginal spending increase if and only if $\xi$ were to exceed the marginal tax cost $\partial T(Y, X) / \partial X$. Of course, individual support for public spending may be motivated by wider considerations than private interest but unless these sort of social concerns are affected by taking out private insurance a comparison of $\xi$ between those with and without private insurance should still be informative about differences in attitudes to public health spending. 
Common sense suggests that the privately insured should be less interested in increasing public spending if only because they do not benefit directly from the proportion spent on elective care. Under the assumptions made above it is also true, albeit that this may be a consideration of secondary importance anyway, that willingness to pay for improved emergency care will also be lower.

Proposition 3.2. Self-interested willingness to pay for public spending increases is lower if privately insured.

Proof From (3.2)

$$
\begin{aligned}
\xi^{0}\left(q^{0}, Q, y^{0}\right)-\xi^{1}\left(q^{1}, Q, y^{1}\right)= & \frac{V_{1}\left(q^{0}, Q, y^{0}\right)}{V_{3}\left(q^{0}, Q, y^{0}\right)} \frac{\partial q^{0}}{\partial X} \\
& +\left[\frac{V_{2}\left(q^{0}, Q, y^{0}\right)}{V_{3}\left(q^{0}, Q, y^{0}\right)}-\frac{V_{2}\left(q^{1}, Q, y^{1}\right)}{V_{3}\left(q^{1}, Q, y^{1}\right)}\right] \frac{\partial Q}{\partial X}
\end{aligned}
$$

The first term is plainly positive and the positivity of the second follows from the assumption that $\frac{\partial}{\partial y}\left(V_{2} / V_{3}\right)>0$ and $\frac{\partial}{\partial q}\left(V_{2} / V_{3}\right) \leq 0$ given that $y^{0}>y^{1}$ and $q^{0}<q^{1}$.

Differences in most desired levels of spending are harder to analyse if considered across ranges of spending which are associated with different choices of private insurance status ie $X^{*}=\arg \max _{X} V^{*}\left(q^{0}(X), q^{1}, Q(X), Y-T(Y, X), \pi(\theta)\right)$. It is common in instances such as this, where private alternatives to public services are available, for preferences not to be single peaked (see, for instance, Stiglitz 1974). Figure 3.1 illustrates the typical situation. The curves labelled $V^{1}$ and $V^{0}$ show utility as a function of public spending on health care $X$ (incorporating the consequences of the implied tax payments) if privately insured and if not. Note that both have been drawn single peaked and the marginal utility of public health spending net of implied tax payments is greater at all points if not privately insured. The peak of the $V^{1}$ curve is also clearly below that of the $V^{0}$ curve indicating that the most preferred level of spending is higher if not privately insured. Nonetheless, recognising that whether or not to be privately insured is chosen according to which gives higher utility, $V^{*}\left(q^{0}(X), q^{1}, Q(X), Y-T(Y, X), \pi(\theta)\right)$ can 
be seen to be represented by the upper envelope of the two curves and that is clearly not single peaked ${ }^{5}$.

The possibly problematic implications of non-single-peakedness for political equilibrium is familiar from the public choice literature. What is of more concern here are the implications for answers to questions on preferred spending levels. It is not clear in such circumstances, for instance, that high, medium and low levels of spending need be naturally ordered in individuals' preferences and this can raise problems for modelling of responses to questions asking individuals to choose between them. This is explored further in the data section below.

\footnotetext{
${ }^{5}$ Of course, this is only a possibility and in some circumstances there would be single peakedness but the possibility considered here is in no way outlandish.
} 


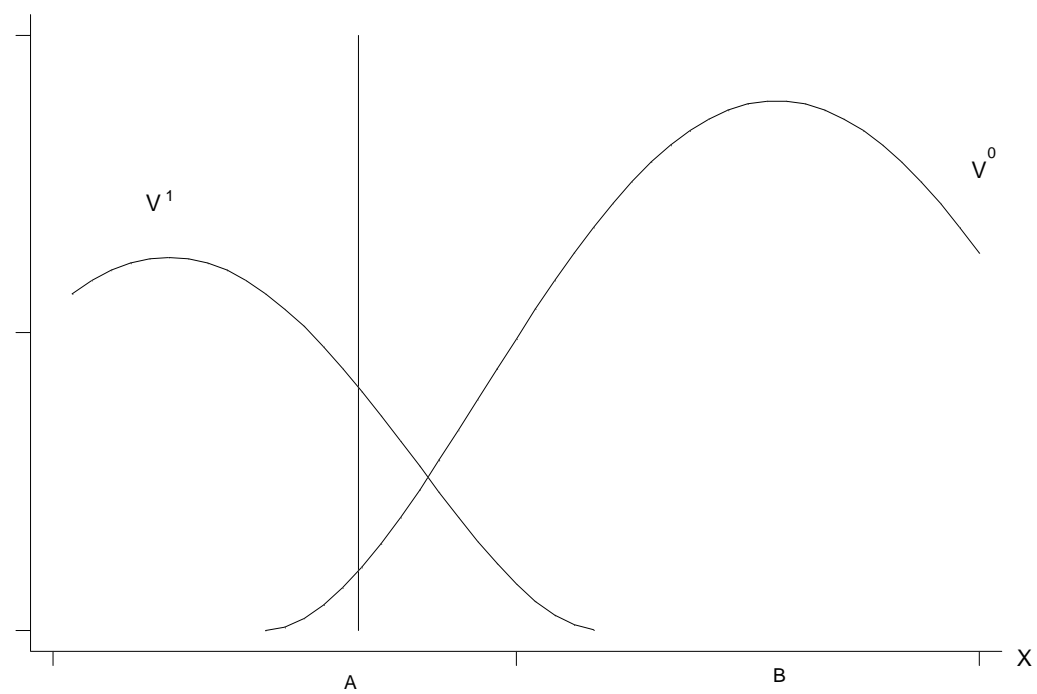

Figure 3.1: Public Spending Preferences with and without Private Insurance 


\section{Data}

To test this model empirically, we draw on two primary sources of data. Individual level data on personal and household characteristics, health insurance decisions and attitudes to public health spending are drawn from the British Social Attitudes (BSA) Survey. Information on temporally and regionally varying indicators of the quality of services provided by the NHS are drawn from Regional Trends.

The BSA is an annual survey of a representative sample of around $3000 \mathrm{UK}$ households which provides detailed data on a wide range of socioeconomic and demographic characteristics including income, occupation, housing tenure, age, sex and household size. In particular, the 1986, 1987, 1989, 1990 and 1991 questionnaires included modules on health. Individuals were asked whether they were covered by private health insurance and, if so, whether the majority of the cost was covered by themselves or by their employer. On average, around $15 \%$ of respondents were covered by private medical insurance during each year of the period with a little over half having the majority of the costs met by their employer.

During this period, the BSA also contained questions regarding attitudes to public spending on health. Two questions, in particular, are of potential interest for our purposes. One of these, included in 1990 and 1991 only (of the years chosen for analysis), asked the following:

Listed below are various areas of government spending. Please show whether you would like to see more or less government spending in each area. Remember that if you say 'much more', it might require a tax increase to pay for it.

This question was asked for eight areas of government spending, including health, education, police and defence. For each of these spending programmes, respondents could choose from five options: "much more", "more", "about the same", "less" or "much less" spending. A greater proportion of respondents chose higher spending on health than for any other spending programme. Combining the two years, $39 \%$ of respondents chose "much more" spending, $52 \%$ "more" and $9 \%$ "about the same" with very few instances of individuals choosing lower levels of public spending.

There are, of course, a number of concerns with the wording of this question. Firstly the tax consequences of spending changes are very unclear. Indeed, no 
reduction in tax liabilities is even indicated if spending cuts are chosen. Furthermore the fact that a possibility of tax increases is indicated only for large increases might be taken to indicate that a small increase could be achieved without tax consequences. Even for large spending increases, where the possibility of tax increases is mentioned (though still only a possibility), incidence is left unclear because the tax instrument is unspecified ${ }^{6}$. This is of concern since the apparent tolerance of higher taxation sits uncomfortably with responses to alternative questions within the BSA which suggest that a large majority of respondents think that their own tax burden is already "high enough".

Furthermore, respondents' attention is not obviously restricted to marginal changes and individuals are not told to consider only their preferences assuming they continue in the same insurance status. This could be problematic given the nature of the theoretical results derived earlier. The possible failure of single peakedness has been explained above. Consider again Figure 3.1 and suppose public expenditure is at A. The individual would choose to be privately insured even though his global optimum would be at B ("much more spending") where public services are of sufficient quality that he would not purchase private medical insurance. However, a move to B could not plausibly be interpreted as a marginal change in expenditure. Preferences at the margin would be for "less" spending. Overall the respondent's preference ordering could plausibly be "much more" followed by "much less", where he relies on private medical insurance for his health care needs and prefers public spending and hence taxation to be as low as possible, followed by "less", "the same" and "a little more". This is plainly not the natural ordering and the possibility of it arising would bring into question, say, the most obvious ordered limited dependent variable methods for modelling answers to the question.

A second question on attitudes to public health spending has several reasons for regarding it as preferable. From a range of spending programmes including education, defence and the environment, respondents are asked:

Here are some items of government spending. Which of them, if any, would be your highest priority for extra spending?

$48 \%$ of respondents chose "health" with a further $32 \%$ choosing education as

\footnotetext{
${ }^{6}$ We have collaborated with data collectors to explore the consequences of being more specific about the nature of the taxes involved in more recent years. Results reported in Hall and Preston (1998) suggest relatively little and poorly determined responsiveness to the implied tax prices.
} 
their top priority for public expenditure. The evidence on attitudes towards public spending on health we obtain from this question appears more suitable for a number of reasons. For one thing, the question was asked in all five years rather than only the final two, offering a greater number of data points. Because the alternative to additional health spending is spending on some other public programme rather than a tax reduction the lack of specificity in implied tax instrument is also much less worrying. Finally it is much more plausibly interpreted as a question about marginal changes (although the amount of the change remains admittedly vague).

We use both questions in our empirical work. Note that even on the most charitable interpretation of the suitability of the first question to our purposes, the estimated equations should differ fundamentally since the nature of the alternatives is different in the two cases - in the first case being additional private income for the respondent and in the second being additional spending on the otherwise most favoured item of public spending. Nonetheless the direction of the private health insurance effect should be the same in the two cases, which is what is mainly of interest in the context of the current paper.

The BSA data has good information concerning respondent's geographic location which we use to merge it with Regional Health Authority level data on public sector health services. Several indicators of public health sector quality are potentially available including length of short and long term waiting lists, total staff, expenditure on diagnosis and treatment, support services and headquarters. Earlier work on the demand for health insurance (Besley, Hall and Preston 1999) has suggested very strongly that it is long term waiting lists that matter most to individuals and this is the only variable used in the empirical work reported below.

\section{Empirical Application}

Within our model, individuals face two margins of choice. First, they must select whether or not to consume elective care services through the private sector by taking out a private medical insurance policy. Second, they must decide attitudes towards public expenditure on health care.

It is likely that these decisions are jointly determined in that common factors which we cannot observe influence both decisions. One possibility is that both de- 
cisions are influenced by concerns over health issues, most particularly because of unobserved aspects of the respondents' own health status. Those who give health issues a particular priority, for instance because more fearful of ill health, may be expected both to be more likely to prioritise increased public health spending over both alternative public spending programmes and lower tax burdens and to be more likely to purchase access to higher quality medical treatment for themselves via a private medical insurance policy. A second possibility is that there may be a shared political component to both the insurance decision and to public attitudes. Those who are hostile to the state may be both more inclined to meet their own medical needs privately and be disinclined to support increased health spending ${ }^{7}$.

Plausible identification of our model therefore requires variables which affect the first stage (insurance purchase) decision but not the second. One possibility is the level of insurance premiums since these may be expected to influence the demand for insurance policies, but given the insurance decision, to have no further impact on public attitudes ${ }^{8}$. However, we do not observe premiums in our data and their use would be problematic anyway if, as commonly occurs, individual characteristics, observed by the insurer but not by us, which are related to the likelihood of requiring medical treatment (and therefore the perceived benefits of improved public services) are also used to determine insurance premiums.

Ideally, identification requires some exogenous variation in premiums between individuals. Since group employment policies allow adverse selection problems to be overcome they may allow cheaper employer-provided insurance. Noting that rates of employer provided insurance differ considerably between industries (see Table 1), we therefore propose to use industry dummies as identifying instruments. The validity of this approach depends on this variation being otherwise unrelated to health spending preferences. We feel safe in discounting the sort of endogeneity that would arise if career (rather than job) choice were driven by the likelihood of employer provision of health insurance. However, we also need to think carefully about the reasons for industry differences in employer-provided insurance coverage. It would be problematic if the source were industry differences in risks of ill health since these could also affect individual attitudes to

\footnotetext{
${ }^{7}$ In this case, endogeneity issues may be far less important when individuals are asked about their priorities between public spending programmes as opposed to their preferences regarding the overall level of public health expenditure.

${ }^{8}$ There may be a small impact through the effect on disposable income but we think it reasonable to neglect this. The statement is true anyhow if made conditional on disposable income.
} 
public health spending but we feel that this is unlikely to be the reason. Major employment-driven episodes of ill health - such as industrial accidents or ill health triggered by exposures to hazardous conditions - would presumably be covered by employer liability insurance rather than employer-provided employee health insurance. A more likely explanation lies in differences in employer costs of medium term employee absence through ill health, these differences being driven, for example, by levels of job-specific human capital.

We adopt a normally-distributed latent variable specification for both private insurance decisions and public spending attitudes. The empirical models estimated are all nested within the following form.

$$
\begin{gathered}
y_{1}=1\left(y_{1}^{*}>0\right) \\
y_{2}=g\left(y_{2}^{*}\right) \\
y_{1}^{*}=X_{1} \beta_{1}+u_{1} \\
y_{2}^{*}=\left(X_{2} \beta_{21}+u_{21}\right) 1\left(y_{1}^{*}>0\right)+\left(X_{2} \beta_{22}+u_{22}\right) 1\left(y_{1}^{*} \leq 0\right) \\
\left(\begin{array}{l}
u_{1} \\
u_{21} \\
u_{22}
\end{array}\right) \sim N\left(\left(\begin{array}{l}
0 \\
0 \\
0
\end{array}\right),\left(\begin{array}{lll}
\sigma_{1}^{2} & \rho_{1} \sigma_{1} \sigma_{21} & \rho_{2} \sigma_{1} \sigma_{22} \\
\rho_{1} \sigma_{1} \sigma_{21} & \sigma_{21}^{2} & \cdot \\
\rho_{2} \sigma_{1} \sigma_{22} & . & \sigma_{22}^{2}
\end{array}\right)\right) .
\end{gathered}
$$

Here $y_{1}$ is purchase of private insurance and $y_{2}$ is either support for higher public health spending or choice of health as top priority for extra spending, depending upon which is being modelled at the time ${ }^{9}$. In the former case $g($. is the measurement function for an ordered probit and in the latter $g($.$) is the$ measurement function for an ordinary probit. As discussed, $X_{1}$ differs from $X_{2}$ in including industry dummies - we report both a Wald test for exclusion of these dummies from (5.2) and a score test for their exclusion from (5.1) ${ }^{10}$. Estimation plainly identifies only the effects of covariates on the probabilities which depend only upon ratios of coefficients to standard errors $\beta_{1} / \sigma_{1}, \beta_{21} / \sigma_{21}$ and $\beta_{22} / \sigma_{22}$.

\footnotetext{
${ }^{9}$ There might be some efficiency gain in modelling answers to the two public spending questions jointly. However, given the uncertainty about the appropriateness of at least one question for the purpose required, we prefer to model them separately so as to avoid contaminating either set of estimates with the consequences of misspecification relating to the other.

${ }^{10}$ This is the obvious analogue of the conventional Sargan test in a linear instrumental variables specification. The test is calculated as the residual sum of squares from regression of a vector of ones on the score contributions (see Gourieroux and Monfort 1995, p.90).
} 
Since respondents are only ever observed in one insurance status no information is ever observed which might identify the lower off-diagonal correlations left blank in $(5.3)$

Note that this "switching coefficients" specification allows all parameters of (5.2) and (5.3) to vary with insurance status. The models are also estimated in the more readily interpretable "intercept shift" form with $\beta_{21} / \sigma_{1}$ and $\beta_{22} / \sigma_{2}$ differing only in the constant terms and $\rho_{1}=\rho_{2}$. The acceptability of the restrictions are assessed though a likelihood ratio test.

Estimation is through maximum likelihood. For the estimates using questions on spending priorities we have all relevant responses for all years but for those using questions on desired spending levels we have answers to these particular questions only in the final two years and the likelihood contributions for earlier years need suitable modification.

\section{Results}

We report estimates in Tables 2 to 5 . In all cases we are comfortably able to accept restriction to an intercept effect only on support for public spending and it is therefore these estimates that are reported in the main text. In each table the first column of results gives the estimates of the private insurance equation, the second that of the public spending attitude equation and the third, for comparison, estimates of a corresponding probit or ordered probit specification in which insurance status has simply been assumed exogenous. In all cases we report marginal probability effects at mean values of other explanatory variables ${ }^{11}$. All results include time effects. We give both results which include and exclude regional health authority (RHA) effects - these could be important if they capture the effects of fixed differences in policy at this administrative level and indeed they are jointly significant in both Tables 2 and 4 .

We first comment briefly on the estimated private insurance demand equations. These are broadly consistent across specifications, as one would hope, and essentially similar to the results of Besley, Hall and Preston (1999). We find that increases in long term waiting lists for hospital treatment within the public sector are associated with a greater take up of private medical insurance. The purchase

\footnotetext{
${ }^{11}$ For support for greater spending this is reported as the effect on the probability of wanting "much more". For dichotomous discrete variables we report the effect of a change of status and for numbers of children and adult we report the effect of adding one more family member.
} 
of insurance is also related to household income ${ }^{12}$ and the highest educational qualification held by the respondent. Educational experience could plausibly capture a permanent income effect, a direct educational effect or be associated with attitudinal changes resulting from experience of higher education. The relationship between demand for private medical insurance and age appears to follow a humped shape peaking between the ages of 40 and 50. This may be explained by a combination of two effects. The elderly typically face an increased likelihood of requiring medical assistance, but for those aged over 60, a sharp increase in premiums is often observed. We find that the number of adults in the household reduces the conditional expectation of the respondent being covered by private medical insurance. Given that income was measured at the household level, this may reasonably be interpreted as an equivalent income effect.

The key effect of interest for the current paper is that of insurance status on support for public health spending. Here the results are remarkably consistent across specifications. An exogenous switch to being privately insured is estimated to reduce the probability of prioritising health spending and that of favouring much more health spending by somewhere between 20 and 25 per cent. These effects are also strongly statistically significant, particularly in the case of prioritisation where effective sample size is larger. Furthermore allowing for endogeneity of the insurance decision appears to be important. Estimates of $\rho$ are consistently just below 0.30 and statistically significant and this is reflected in the fact that the bivariate ML estimates are substantially more negative than would have been found using an ordinary probit or ordered probit. This is consistent with the presence of correlated omitted heterogeneity associated with a general preference for health-related goods and probably concerning unobserved aspects of health status. The other effect which might be expected to be common between the two cases is that of waiting lists but disappointingly this figures significantly in none of the attitudinal equations.

It is interesting that the effects of other variables are quite different between the two different measures of attitude and that they are so in ways which are readily interpretable. It was noted above that the nature of the alternatives

\footnotetext{
${ }^{12}$ Our income variable needs a little explanation. Income data in the BSA is banded and the bands are fixed in nominal terms across years. To avoid problems of comparability we assign each respondent to the mean position within the income distribution of those households in the same band in the same year. The associated coefficients therefore capture the effects of movement up the income distribution. The time dummies will pick up the effects of income growth.
} 
differ fundamentally in the two cases, being money in the pocket in the case of the support for higher spending question and spending on the next most preferred programme in the case of the priorities question. Much the most popular spending item after health is education. It is therefore notable that economic effects such as employment status and housing tenure come through more strongly in the former case, whereas educational and demographic effects emerge more strongly in the latter. In particular, female respondents, those with children and those with good educational backgrounds are markedly less likely to prioritise health as against education as a candidate for increased spending. A humped relationship to age of respondent is evident in the case of both questions.

Importantly for the plausibility of our econometric procedures, the industry dummies used to instrument insurance status are jointly strongly significant in the insurance equation while we are unable in any instance to reject exclusion from the equations capturing attitudes to spending ${ }^{13}$.

\section{Discussion}

Many parts of the public sector coexist with private provision of similar services and in such circumstances we may expect to find interaction between public and private choices. Quality of publicly provided services will be a central influence on decisions whether to make use of private substitutes and use of private substitutes will feed back into attitudes towards the level of public spending. In earlier research, we found evidence that quality of health services provided by the public sector was associated with take up of private medical insurance (Besley, Hall and Preston,1999). In this paper we have shown evidence also that individual take up of private medical insurance inhibits support for spending on the public health sector $^{14}$. Such effects have been shown to be appreciable and allowance for the joint determination of insurance decisions and attitudes magnifies the size of the

\footnotetext{
${ }^{13}$ Note that the nonlinearity in the specification allows us formally to include all industry dummies in the insurance equation without losing identification. The degrees of freedom are therefore equal to the number of excluded dummies. To the extent that this is a consequence of functional form assumptions, it is reassuring to note that none of the score tests quoted would reject if degrees of freedom were reduced by one.

${ }^{14}$ We have already observed that aggregate take-up rates will have an offsetting reducing effect on the cost of health provision for those without private insurance. Insofar as any such effects are present they would enter our estimates through the time dummies and be inseparable in our data from other aggregate time series effects.
} 
estimated effects. Assessing the extent to which these interactions could render the public spending equilibrium sensitive to changes in costs and other aspects of the policy making context requires however a greater understanding of the manner in which public preferences translate themselves into policy decisions. 
Table 1

Employer provided private health insurance by industrial sector

\begin{tabular}{lcc} 
& Proportion & Sample \\
\hline Agriculture & 0.045 & 157 \\
Energy and Water & 0.057 & 264 \\
Metals/Minerals Extraction & 0.126 & 382 \\
Metal Goods Engineering & 0.086 & 1098 \\
Other Manufacturing & 0.088 & 1131 \\
Construction & 0.090 & 603 \\
Distribution & 0.079 & 1927 \\
Transport and Communication & 0.070 & 603 \\
Financial Services & 0.219 & 898 \\
Other Services & 0.060 & 3270 \\
\hline
\end{tabular}

Source: British Social Attitudes Survey 
Table 2

Priority for extra public spending (Regional health authority effects included)

\begin{tabular}{|c|c|c|c|c|c|c|}
\hline & \multicolumn{2}{|c|}{ Private Insurance } & \multicolumn{4}{|c|}{ Attitude to Public Spending } \\
\hline & & & \multicolumn{2}{|c|}{ Bivariate $M L$} & \multicolumn{2}{|l|}{ Probit } \\
\hline & Coefficient & t-value & Coefficient & t-value & Coefficient & t-value \\
\hline Private insurance & & & -0.250 & 4.257 & -0.057 & 3.92 \\
\hline NHS Quality & & & & & & \\
\hline Long term waiting list & 0.117 & 1.858 & -0.024 & 0.224 & -0.046 & 0.44 \\
\hline Socioeconomic & & & & & & \\
\hline Household income & 0.364 & 24.380 & 0.093 & 2.607 & 0.008 & 0.32 \\
\hline GCSE education & 0.047 & 5.181 & -0.021 & 1.552 & -0.029 & 2.15 \\
\hline A Level education & 0.071 & 7.465 & -0.049 & 3.257 & -0.062 & 4.34 \\
\hline Degree education & 0.052 & 4.034 & -0.166 & 7.751 & -0.177 & 8.43 \\
\hline Self employed & -0.028 & 2.848 & -0.035 & 1.802 & -0.030 & 1.55 \\
\hline Manufacturing & -0.026 & 1.381 & 0.014 & 1.278 & 0.015 & 1.33 \\
\hline Owner occupier & 0.041 & 5.073 & 0.029 & 2.368 & 0.025 & 2.08 \\
\hline Demographic & & & & & & \\
\hline Age & 0.982 & 8.538 & 0.727 & 4.328 & 0.571 & 3.49 \\
\hline $\mathrm{Age}^{2}$ & -0.899 & 7.373 & -0.804 & 4.804 & -0.678 & 4.10 \\
\hline Female & 0.002 & 0.271 & 0.045 & 4.355 & 0.046 & 4.45 \\
\hline Number of children & -0.003 & 1.139 & -0.034 & 6.592 & -0.034 & 6.56 \\
\hline Number of adults & -0.023 & 6.639 & -0.006 & 0.926 & 0.001 & 0.10 \\
\hline$\rho$ & & & 0.292 & 3.346 & & \\
\hline Time dummies & & & Yes & & & \\
\hline RHA dummies & & & Yes & & & \\
\hline Sample size & & & 659 & & & \\
\hline
\end{tabular}

LR test for intercept effect only: $\chi_{33}^{2}=14.68(p=0.998)$

Wald test for exclusion of industry effects from private insurance equation:

$$
\chi_{10}^{2}=68.17(p=0.000)
$$

Wald test for exclusion of RHA effects

$$
\chi_{30}^{2}=71.73(p=0.000)
$$

Score test for exclusion of industry effects from public spending equation:

$$
\chi_{10}^{2}=12.05(p=0.282)
$$




\section{Table 3}

Priority for extra public spending (No regional health authority effects)

\begin{tabular}{|c|c|c|c|c|c|c|}
\hline & \multirow{2}{*}{\multicolumn{2}{|c|}{ Private Insurance }} & \multicolumn{4}{|c|}{ Attitude to Public Spending } \\
\hline & & & \multicolumn{2}{|c|}{ Bivariate $M L$} & \multicolumn{2}{|l|}{ Probit } \\
\hline & Coefficient & t-value & Coefficient & t-value & Coefficient & t-value \\
\hline Private insurance & & & -0.239 & 3.982 & -0.057 & 3.91 \\
\hline NHS Quality & & & & & & \\
\hline $\begin{array}{l}\text { Long term waiting list } \\
\text { Socioeconomic }\end{array}$ & 0.163 & 4.667 & -0.031 & 0.524 & -0.065 & 1.14 \\
\hline Household income & 0.376 & 25.625 & 0.093 & 2.557 & 0.011 & 0.42 \\
\hline GCSE education & 0.046 & 5.156 & -0.022 & 1.621 & -0.029 & 2.19 \\
\hline A Level education & 0.070 & 7.454 & -0.050 & 3.347 & -0.063 & 4.40 \\
\hline Degree education & 0.056 & 4.270 & -0.163 & 7.652 & -0.175 & 8.34 \\
\hline Self employed & -0.028 & 2.809 & -0.034 & 1.734 & -0.029 & 1.50 \\
\hline Manufacturing & -0.028 & 1.459 & 0.014 & 1.222 & 0.014 & 1.28 \\
\hline Owner occupier & 0.040 & 5.041 & 0.024 & 2.001 & 0.021 & 1.74 \\
\hline Demographic & & & & & & \\
\hline Age & 0.987 & 8.609 & 0.717 & 4.264 & 0.569 & 3.48 \\
\hline $\mathrm{Age}^{2}$ & -0.898 & 7.390 & -0.797 & 4.761 & -0.678 & 4.11 \\
\hline Female & 0.002 & 0.279 & 0.046 & 4.421 & 0.047 & 4.50 \\
\hline Number of children & -0.004 & 1.423 & -0.035 & 6.700 & -0.035 & 6.62 \\
\hline Number of adults & -0.024 & 6.823 & -0.006 & 0.801 & 0.001 & 0.18 \\
\hline$\rho$ & & & 0.275 & 3.098 & & \\
\hline Time dummies & & & Yes & & & \\
\hline RHA dummies & & & No & & & \\
\hline Sample size & & & 659 & & 106 & \\
\hline
\end{tabular}

LR test for intercept effect only: $\chi_{18}^{2}=12.22(p=0.835)$

Wald test for exclusion of industry effects from private insurance equation:

$$
\chi_{10}^{2}=70.78(p=0.000)
$$

Score test for exclusion of industry effects from public spending equation:

$$
\chi_{10}^{2}=12.29(p=0.266)
$$


Table 4

Support for greater public spending

(Regional health authority effects included)

\begin{tabular}{|c|c|c|c|c|c|c|}
\hline & \multicolumn{2}{|c|}{ Private Insurance } & \multicolumn{4}{|c|}{ Attitude to Public Spending } \\
\hline & & & \multicolumn{2}{|c|}{ Bivariate $M L$} & \multicolumn{2}{|l|}{ Probit } \\
\hline & Coefficient & t-value & Coefficient & t-value & Coefficient & t-value \\
\hline Private insurance & & & -0.218 & 2.534 & -0.050 & 2.07 \\
\hline NHS Quality & & & & & & \\
\hline Long term waiting list & 0.116 & 1.824 & 0.157 & 0.820 & 0.136 & 0.71 \\
\hline Socioeconomic & & & & & & \\
\hline Household income & 0.362 & 24.215 & 0.003 & 0.051 & -0.082 & 1.83 \\
\hline GCSE education & 0.047 & 5.131 & -0.027 & 1.120 & -0.034 & 1.43 \\
\hline A Level education & 0.071 & 7.507 & -0.008 & 0.330 & -0.020 & 0.80 \\
\hline Degree education & 0.056 & 4.255 & -0.016 & 0.459 & -0.024 & 0.69 \\
\hline Self employed & -0.027 & 2.808 & -0.085 & 2.781 & -0.081 & 2.62 \\
\hline Manufacturing & -0.028 & 1.475 & 0.006 & 0.292 & 0.007 & 0.32 \\
\hline Owner occupier & 0.040 & 4.925 & -0.097 & 4.376 & -0.102 & 4.58 \\
\hline Demographic & & & & & & \\
\hline Age & 0.989 & 8.362 & 0.789 & 2.765 & 0.642 & 2.31 \\
\hline $\mathrm{Age}^{2}$ & -0.909 & 7.217 & -0.980 & 3.502 & -0.859 & 3.12 \\
\hline Female & 0.002 & 0.353 & 0.012 & 0.662 & 0.012 & 0.68 \\
\hline Number of children & -0.004 & 1.353 & -0.001 & 0.060 & -0.000 & 0.03 \\
\hline Number of adults & -0.024 & 6.715 & 0.016 & 1.260 & 0.023 & 1.87 \\
\hline$\rho$ & & & 0.285 & 2.057 & & \\
\hline Time dummies & & & Yes & & & \\
\hline RHA dummies & & & Yes & & & \\
\hline Sample size & & & 659 & & & \\
\hline
\end{tabular}

LR test for intercept effect only: $\chi_{31}^{2}=8.37(p=1.000)$

Wald test for exclusion of industry effects from private insurance equation:

$$
\chi_{10}^{2}=70.28(p=0.000)
$$

Wald test for exclusion of RHA effects

$$
\chi_{30}^{2}=73.53(p=0.000)
$$

Score test for exclusion of industry effects from public spending equation:

$$
\chi_{10}^{2}=12.75(p=0.238)
$$




\section{Table 5}

Support for greater public spending

(No regional health authority effects)

\begin{tabular}{|c|c|c|c|c|c|c|}
\hline & \multirow{2}{*}{\multicolumn{2}{|c|}{ Private Insurance }} & \multicolumn{4}{|c|}{ Attitude to Public Spending } \\
\hline & & & \multicolumn{2}{|c|}{ Bivariate $M L$} & \multicolumn{2}{|l|}{ Probit } \\
\hline & Coefficient & t-value & Coefficient & t-value & Coefficient & t-value \\
\hline Private insurance & & & -0.222 & 2.604 & -0.049 & 2.05 \\
\hline NHS Quality & & & & & & \\
\hline $\begin{array}{l}\text { Long term waiting list } \\
\text { Socioeconomic }\end{array}$ & 0.165 & 4.731 & -0.040 & 0.420 & -0.078 & 0.83 \\
\hline Household income & 0.375 & 25.455 & 0.002 & 0.036 & -0.088 & 2.01 \\
\hline GCSE education & 0.046 & 5.154 & -0.027 & 1.117 & -0.035 & 1.44 \\
\hline A Level education & 0.071 & 7.529 & -0.006 & 0.250 & -0.019 & 0.75 \\
\hline Degree education & 0.059 & 4.478 & -0.013 & 0.366 & -0.022 & 0.64 \\
\hline Self employed & -0.07 & 2.752 & -0.087 & 2.866 & -0.083 & 2.70 \\
\hline Manufacturing & -0.029 & 1.549 & 0.007 & 0.323 & 0.007 & 0.35 \\
\hline Owner occupier & 0.039 & 4.894 & -0.103 & 4.685 & -0.107 & 4.88 \\
\hline Demographic & & & & & & \\
\hline Age & 0.997 & 8.463 & 0.766 & 2.687 & 0.614 & 2.21 \\
\hline $\mathrm{Age}^{2}$ & -0.911 & 7.265 & -0.964 & 3.450 & -0.841 & 3.06 \\
\hline Female & 0.002 & 0.372 & 0.014 & 0.751 & 0.014 & 0.77 \\
\hline Number of children & -0.005 & 1.630 & -0.000 & 0.006 & 0.000 & 0.03 \\
\hline Number of adults & -0.024 & 6.894 & 0.018 & 1.430 & 0.025 & 2.07 \\
\hline$\rho$ & & & 0.293 & 2.133 & & \\
\hline Time dummies & & & Yes & & & \\
\hline RHA dummies & & & No & & & \\
\hline Sample size & & & 659 & & & \\
\hline
\end{tabular}

LR test for intercept effect only: $\chi_{16}^{2}=5.62(p=0.992)$

Wald test for exclusion of industry effects from private insurance equation:

$$
\chi_{10}^{2}=72.58(p=0.000)
$$

Score test for exclusion of industry effects from public spending equation:

$$
\chi_{10}^{2}=12.62(p=0.246)
$$




\section{References}

[1] Barzel, Y., 1973, Private schools and public schools and public school finance, Journal of Political Economy 81,174-186.

[2] Besley, T. and Coate, S. 1991 Public provision of private goods and the redistribution of income, American Economic Review 81, 979-984.

[3] Besley, T., Hall, J. and Preston, I. 1996a Private health insurance and the state of the NHS. IFS Commentary No. 52. Institute for Fiscal Studies, London

[4] Besley, T., Hall, J. and Preston, I. 1999 The demand for private health insurance: do waiting lists matter? Journal of Public Economics, forthcoming

[5] Blackorby, C. and D. Donaldson, 1988, Cash versus kind, self-selection and efficient transfers, American Economic Review 78, 691-700.

[6] Bosanquet, N. and Pollard, S. (1997) Ready for treatment: Public expectations and the future of health care. Social Market Foundation, London.

[7] Brook, L., Hall, J. and Preston, I. 1998 What drives support for public spending? in P.F. Taylor Gooby (ed) Choice and Public Policy, Macmillan, London

[8] Casamatta, G., H. Cremer and P. Pestieau 1997 On the political sustainability of redistributive social insurance systems, paper presented at ISPE Conference, Oxford, December 1997.

[9] Cutler, D. and J. Gruber, 1996, Does public insurance crowd out private insurance? Quarterly Journal of Economics 111, 391-430.

[10] Epple, D. and R. Romano, 1996a, Public provision of private goods, Journal of Political Economy 104, 57-84.

[11] Epple, D. and R. Romano, 1996b, Ends against the middle: Determining public service provision when there are private alternatives, Journal of Public Economics 62, 297-325. 
[12] Glomm, G. and B. Ravikumar, 1998, Opting out of publicly provided services: A majority voting result, Social Choice and Welfare 15, 187-199..

[13] Gourieroux, C. and A. Monfort 1995 Statistics and econometric models, Vol 2, Cambridge University Press, Cambridge.

[14] Gouveia, M., 1996, Majority rule and the public provision of a private good, Public Choice 93, 221-244.

[15] Hall, J. and I. Preston 1998 Tax price effects on attitudes to hypothecated tax increases, IFS Working Paper W98/6, Institute for Fiscal Studies, London.

[16] Labour Party, 1997 Britain Deserves Better, London.

[17] Stiglitz, J. E., 1974, The demand for education in public and private school systems, Journal of Public Economics 3, 349-385. 


\section{Data Appendix}

Mean

Dependent variables

Private insurance $\quad 0.153$

Support for more public health spending $\quad 0.518$

Support for much more public health spending 0.386

Health top priority for extra public spending $\quad 0.534$

Categorical variables

Female 0.534

GCSE education $^{15} \quad 0.265$

A Level education $^{16} \quad 0.237$

Degree education $^{17} \quad 0.080$

Self employed $\quad 0.073$

Manufacturing $\quad 0.295$

Owner occupier 0.695

Continuous variables

Mean Standard deviation

Long term waiting list (persons per 100) $\quad 0.293 \quad 0.118$

Household income (proportion) $)^{18} \quad 0.520 \quad 0.285$

Number of children (persons) $\quad 0.715 \quad 1.041$

Number of adults (persons) $\quad 2.122 \quad 0.823$

$\begin{array}{lll}\text { Age (years /100) } & 0.462 & 0.173\end{array}$

\footnotetext{
${ }^{15}$ Respondent's highest educational qualification is GCSE or equivalent (typically taken at age 16)

${ }^{16}$ Respondent's highest educational qualification is A Level or equivalent (typically taken at age 18)

${ }^{17}$ Respondent has a degree level educational qualification

${ }^{18}$ Household income is measured by the mean position in the income distribution of households with the same banded income in the same year (in the whole BSA sample).
} 